\title{
APLICAÇÃO DO MMGP PARA ANÁLISE DO NÍVEL DE MATURIDADE E PROPOSTA DE IMPLANTAÇÃO DO EGP EM UMA EMPRESA DE ENGENHARIA MULTIDISCIPLINAR NO RIO DE JANEIRO
}

\author{
APPLICATION OF MMGP FOR ANALYSIS OF THE MATURITY LEVEL AND PROPOSAL TO \\ IMPLEMENT THE PMO IN A MULTIDISCIPLINARY ENGINEERING COMPANY IN RIO DE \\ JANEIRO
}

Resumo

Vinícius Porto dos Santos Cruz Mestrado Profissional em Sistemas de Gestão Universidade Federal Fluminense - UFF Niterói, Rio de Janeiro - Brasil viniciuspscruz@hotmail.com

Marcos Alexander Barbosa Gomes MBA em Gerenciamento de Projetos Fundação Getúlio Vargas - FGV Rio de Janeiro, Rio de Janeiro - Brasil mgomes_fis@hotmail.com

Fernando Oliveira de Araujo Pós-Doutorado em Engenharia de Produção Universidade Federal Fluminense - UFF Niterói, Rio de Janeiro - Brasil fernandoaraujo@id.uff.br

O presente artigo tem por objetivo analisar o nível de maturidade de uma empresa de engenharia multidisciplinar localizada no Rio de Janeiro no que concerne às suas práticas em gerenciamento de projetos e propor uma alternativa estruturada para o amadurecimento dos seus processos gerenciais visando promover a melhoria do desempenho de seus projetos. De modo a subsidiar a referida análise, em termos teóricos, o estudo apoia-se no levantamento sistemático da literatura. Em termos empíricos, realiza a investigação do nível de maturidade em gerenciamento de projetos através da aplicação do Modelo de Maturidade em Gerenciamento de Projetos (MMGP) e realização de entrevistas junto aos gerentes de projeto e a alta direção da empresa, com vistas a confrontar a percepção destes no que tange aos padrões de boas práticas em gerenciamento de projetos evidenciados na literatura. Como resultado, o estudo confirma um nível de maturidade inicial em gerenciamento de projetos, com distorção considerável entre as percepções dos grupos de respondentes, apontando os principais problemas no desenvolvimento de projetos. Em face das distorções e do baixo nível de maturidade analisados, propõe-se um modelo para implantação de um Escritório de Gerenciamento de Projetos (EGP) como mecanismo adequado para criação e melhoria contínua de processos, metodologias e padrões para planejamento e controle dos projetos futuros.

Palavras-chave: Modelos de Maturidade em Gerenciamento de Projetos. MMGP. Escritório de Gerenciamento de Projetos. EGP. Gerenciamento de Projetos.

\begin{abstract}
This article aims to analyze the maturity level of a multidisciplinary engineering company located in Rio de Janeiro with regard to its practices in project management and to propose a structured alternative for the maturation of its management processes in order to promote performance improvement of your projects. In order to support this analysis, in theoretical terms, the study is supported by a systematic survey of the literature. In empirical terms, it investigates the level of maturity in project management by applying the Project Management Maturity Model (MMGP) and conducting interviews with project managers and the company's top management, in order to confront their perception regarding the standards of good practices in project management evidenced in the literature. As a result, the study confirms a level of initial maturity in project management, with considerable distortion between the perceptions of the groups of respondents, pointing out the main
\end{abstract}


problems in project development. In view of the distortions and the low level of maturity analyzed, a model for the implementation of a Project Management Office (PMO) is proposed as an adequate mechanism for the creation and continuous improvement of processes, methodologies and standards for planning and controlling future projects.

Keywords: Maturity Models in Project Management. MMGP. Project Management Office. PMO. Project management.

\section{Cite como - American Psychological Association (APA)}

Cruz, V. P. dos S., Gomes, M. A. B., \& Araujo, F. O. de (2020, maio/ago.). Aplicação do MMGP para análise do nível de maturidade e proposta de implantação do EGP em uma empresa de engenharia multidisciplinar no Rio de Janeiro. Revista de Gestao e Projetos (GeP), 11(2), 133-158. https://doi.org/10.5585/gep.v11i2.16905.

\section{Introdução}

O crescimento da demanda para adoção de conhecimentos e práticas em gerenciamento de projetos a fim de realizar trabalhos em setores e indústrias distintos, aceleraram o processo de "projetização" das organizações, que significa a adaptação e implementação de uma estrutura organizacional, métodos e meios para realizar as atividades de projetos (Winter \& Szczepanek, 2008; Kwak, Sadatsafavi, Walewski, \& Williams, 2015). Nesse sentido, os projetos são concebidos para operacionalizar objetivos estratégicos ou para atender a s necessidades operacionais de uma organização (Anantatmula \& Rad, 2018). Pela natureza de seus entregáveis, tais organizações estrategicamente baseadas em projetos são exigidas a trabalharem numa estrutura de projetos (Müller, Drouin, \& Sankaran, 2019).

A necessidade de uma nova abordagem levou ao crescimento do gerenciamento de projetos nas últimas décadas como uma disciplina formal bem estabelecida em vários setores e, para introduzir esses novos processos e métodos de gerenciamento, as organizações passam por uma reestruturação organizacional dos modelos de negócios para melhorar seu desempenho (Oliveira, Tereso, \& Fernandes, 2017). De acordo com Oliveira e Martins (2018), cada vez mais está sendo aceito pelos altos executivos que o trabalho orientado por projetos tenha um ponto central de apoio dentro da organização para contribuir com a sistematização e $\quad$ o alinhamento estratégico dos projetos.

Operar em diferentes mercados com velocidades e maturidades distintas apresenta inúmeras dificuldades em termos de padronização, comunicação e aprendizado (Sergeeva \& Ali, 2020). Dessa maneira, a implantação do Escritório de Gerenciamento de Projetos (EGP) é uma prática moderna de gestão que vem ganhando notoriedade (Oliveira \& Martins, 2018). 
Anantatmula (2010), menciona que o EGP é uma abordagem para promover a maturidade em gerenciamento de projetos de uma organização devido às suas funções de desenvolver processos e práticas na adoção de ferramentas e técnicas para o planejamento de projetos e portfólios. Segundo Backlund, Chronéer e Sundqvist (2014), pesquisas indicam que é esperado que organizações com níveis mais altos de maturidade em gerenciamento de projetos obtenham sucesso na execução dos seus projetos e, portanto, possuem uma vantagem competitiva no mercado.

$\mathrm{O}$ mercado de engenharia de projetos multidisciplinares no âmbito nacional apresenta uma forte competitividade com diversos players que atuam no segmento. Em um cenário cada vez mais concorrido e maiores exigências dos clientes, muitas empresas comprometem-se a entregar resultados com recursos insuficientes, apenas para se manterem ativas no mercado.

O presente estudo tem como objeto uma empresa de engenharia multidisciplinar com atuação no Rio de Janeiro, cuja falta de padronização e promoção da melhoria contínua nos processos de planejamento, execução e medição de seus projetos, se apresenta como uma oportunidade de aperfeiçoamento. Apesar de sua estrutura orientada a projetos, a ausência de uma linguagem homogênea e da aplicação de boas práticas no gerenciamento dos projetos, faz com que os prazos, o escopo e a qualidade de algumas de suas entregas fiquem, ao final do projeto, fora dos requisitos estabelecidos pelos clientes. Em um levantamento interno realizado no segundo semestre de 2018 sobre os projetos desenvolvidos nos últimos seis anos, a falha no gerenciamento de escopo se mostrou como o maior fator de risco para as entregas que foram realizadas $(45 \%)$, seguida de falhas no gerenciamento do cronograma (15\%) e integração (10\%), sendo as outras áreas de conhecimento conforme PMI (2017), o percentual restante. Como resultado de tais falhas, $70 \%$ dos projetos entregues no período foram alvo de retrabalho, aumentando seus custos e retendo equipes em projetos simultâneos.

As circunstâncias supracitadas sucederam em um problema de dimensão organizacional, cerne deste trabalho: não há processos e práticas de gerenciamento de projetos estabelecidos na empresa, o que dificulta a criação de um corpo de conhecimento com identidade organizacional para implantação dos projetos, além dos impactos já identificados na performance de projetos anteriores supramencionados. Os pontos elencados trazem à tona a questão central da pesquisa: qual a alternativa capaz de contribuir com o amadurecimento dos processos gerencias e o desempenho dos projetos da organização em estudo?

Dessa forma, o objetivo deste estudo é, com base na literatura especializada e na investigação empírica, analisar o nível de maturidade da empresa em questão no que 
concerne às suas práticas em gerenciamento de projetos e propor uma alternativa estruturada para o amadurecimento dos seus processos gerenciais, visando promover a melhoria do desempenho de seus projetos.

Em termos de organização, o presente trabalho encontra-se subdividido em cinco distintas seções, sendo este primeira a que oferece um preâmbulo quanto à relevância na adoção de boas práticas em gerenciamento de projetos, além de evidenciar o problema de pesquisa e o objetivo do presente estudo. A seção 2 sumariza resultados advindos da revisão da literatura, trazendo à baila os principais conceitos e fundamentos capazes de apoiar a investigação de campo e os resultados. $\mathrm{Na}$ seção 3 encontram-se descritos os procedimentos metodológicos da pesquisa empírica. Na seção 4 são analisados e discutidos os resultados da pesquisa. Na quinta e última seção são descritas as conclusões e sugestões de estudos futuros.

\section{Revisão da literatura}

Para identificar trabalhos que pudessem contribuir para o desenvolvimento da fundamentação teórica e que fossem aderentes ao tema central do estudo, realizouse uma revisão da literatura através do uso das palavras-chave apresentadas neste trabalho. Os resultados são apresentados nas subseções a seguir.

\subsection{Escritório de gerenciamento de projetos e o alinhamento estratégico de projetos}

Devido à importância que os projetos têm obtido no âmbito das organizações, o tema Escritório de Gerenciamento de Projetos (EGP) tem sido constantemente pauta de publicações especializadas em gerenciamento de projetos (Rodrigues, Júnior, \& Csillag, 2006). Para Hobbs e Aubry (2007), estudar o papel do EGP é um meio prático para estudar o gerenciamento de projetos como é praticado nas organizações.

O EGP é entendido de maneiras diferentes por autores distintos, podendo ser definido como: uma consultoria interna de padronização de processos e experiência elevada em gerenciamento de projetos (Too \& Weaver, 2014); uma entidade organizacional de excelência em gestão e apoio à tomada de decisão (Szalay, Kovacsb, \& Sebestyenc, 2017); uma unidade organizacional responsável por estruturar, gerenciar e implantar práticas de gestão alinhadas à estratégia empresarial (Anantatmula \& Rad, 2018); um órgão corporativo de coordenação e otimização para o gerenciamento do portfólio de projetos (Bredillet, Tywoniak, \& Tootoonchy, 2018); uma instituição de governança para projetos inserida na estrutura da governança corporativa de uma empresa (Müller et al., 2019) e; o facilitador da transferência de conhecimento entre os diversos níveis dentro de uma organização (Sergeeva \& Ali, 2020). 
Pesquisas sobre a natureza, o papel e a estrutura de gestão de um EGP nas organizações têm obtido relevância no âmbito do gerenciamento de projetos. Distintas tipologias e funções são encontradas na literatura especializada (Andersen, Henriksen, \& Aarseth, 2006; Desouza \& Evaristo, 2006; Hobbs \& Aubry, 2007; Martins, Moura, \&
Mesquita, 2011; Too \& Weaver, 2014; Monteiro, Santos, \& Varajão, 2016; Szalay et al., 2017; Bredillet et al., 2018; Otra-Aho, Iden, \& Hallikas, 2019; Sergeeva \& Ali, 2020). Jalal e Koosha (2015) apresentam um resumo de funções e atividades de um EGP identificados em seu trabalho, conforme mostra o Quadro 1.

Quadro 1 - Principais funções de um EGP

\begin{tabular}{|c|l|}
\hline$\#$ & \multicolumn{1}{c|}{ Funções } \\
\hline 1 & Desenvolvimento de metodologias de gerenciamento de projetos \\
\hline 2 & Desenvolvimento de ferramentas e software de gerenciamento de projetos \\
\hline 3 & Gerenciamento de lições aprendidas e do conhecimento \\
\hline 4 & $\begin{array}{l}\text { Treinamento e desenvolvimento de competências em gerenciamento de } \\
\text { projetos }\end{array}$ \\
\hline 5 & Mentoring e coaching em gerenciamento de projetos \\
\hline 6 & Governança e desenvolvimento de recursos humanos \\
\hline 7 & Monitoramento e Controle de Projetos \\
\hline 8 & Gerenciamento de portfólio \\
\hline 9 & Participação no planejamento estratégico \\
\hline 10 & Gerenciamento de interface com clientes \\
\hline 11 & Gerenciamento de interface entre vendedor e contratante \\
\hline
\end{tabular}

Fonte: Adaptado de Jalal e Koosha (2015).

Segundo Hobbs e Aubry (2007), os EGPs são entidades organizacionais e suas dimensões variam significativamente de uma organização para outra, devendo se acomodar conforme as necessidades de uma determinada empresa. O critério principal para o sucesso do EGP é que sua estrutura esteja alinhada com a cultura corporativa da empresa (Desouza \& Evaristo, 2006). Anantatmula e Rad (2018) estabelecem que, como etapa inicial para a implementação do EGP, a organização deve determinar os objetivos organizacionais e persegui-los, pois, existe um vínculo estreito entre o comprometimento, $\mathrm{o}$ apoio, $\mathrm{o}$ financiamento da alta gerência e o cumprimento desses objetivos.

De acordo com Martins et al. (2011), o EGP se apresenta como um elemento para auxiliar as organizações a gerenciarem melhor seus empreendimentos, mediante a implementação de uma estrutura formal, seja ajudando a minimizar os riscos associados, seja diminuindo os conflitos inerentes entre projetos e operações ou, mesmo, provendo metodologias adequadas.

Sergeeva e Ali (2020) elencam várias maneiras pelas quais as empresas orientadas a projetos podem equipar seus EGPs com recursos para facilitar a exploração do 
conhecimento existente. Os autores exemplificam atribuindo aos EGPs a responsabilidade pelo design e distribuição de templates de projetos, pelas diretrizes e checklists para conduzir projetos (como avaliação de riscos, lições aprendidas, controle da qualidade, modelos de orçamento e checklists) e de apoiar os gerentes de projeto na metodologia (Sergeeva \& Ali, 2020).

Ko e Kim (2019) analisaram o impacto do alinhamento estratégico dos negócios na eficiência do EGP. Segundo os autores, o ambiente de negócios nos dias de hoje atinge os objetivos estratégicos corporativos através da operação bem-sucedida das atividades de projetos. Isto posto, o papel do EGP no gerenciamento desses projetos é, portanto, atingir os objetivos estratégicos da empresa vinculando projetos e objetivos de negócios e não apenas os objetivos clássicos de conclusão bem-sucedida do projeto dentro do cronograma e do orçamento. Portanto, a eficiência do EGP pode ser influenciada pela forma como estes projetos estão alinhados aos objetivos de negócios da empresa (Ko \& Kim, 2019).

As funções e processos do EGP oferecem uma maneira de integrar os ativos da organização e criar novos ativos. Os processos atuam para criar um conjunto coerente de ativos para maximizar a criação de valor da empresa (Otra-Aho et al., 2019). De acordo Szalay et al. (2017), os serviços e grupos de serviços essenciais de um EGP serão identificados não apenas em fornecer informações essenciais e práticas suporte no nível do projeto, mas em conduzir mudanças organizacionais, os resultados de negócios e na mensuração do desempenho dos projetos.

\subsection{Maturidade em gerenciamento de projetos}

A plena maturidade em gerenciamento de projetos refere-se a um estado em que a organização está em perfeitas condições para atingir seus objetivos de acordo com o seu grau de estruturação para o gerenciamento de seus projetos (Backlund et al., 2014), ao estabelecimento e comprovação de práticas e procedimentos inovadores que levam ao sucesso o planejamento e a execução dos projetos (Anantatmula \& Rad, 2018) e a implementação de metodologias, padrões e processos de acompanhamento que possuem alta probabilidade de sucesso repetido dos projetos (Almeida \& Neto, 2015). A Figura 1 ilustra de forma geral, as métricas para medição da maturidade em projetos. 
Figura 1 - Fatores de medição da Maturidade em Gerenciamento de Projetos

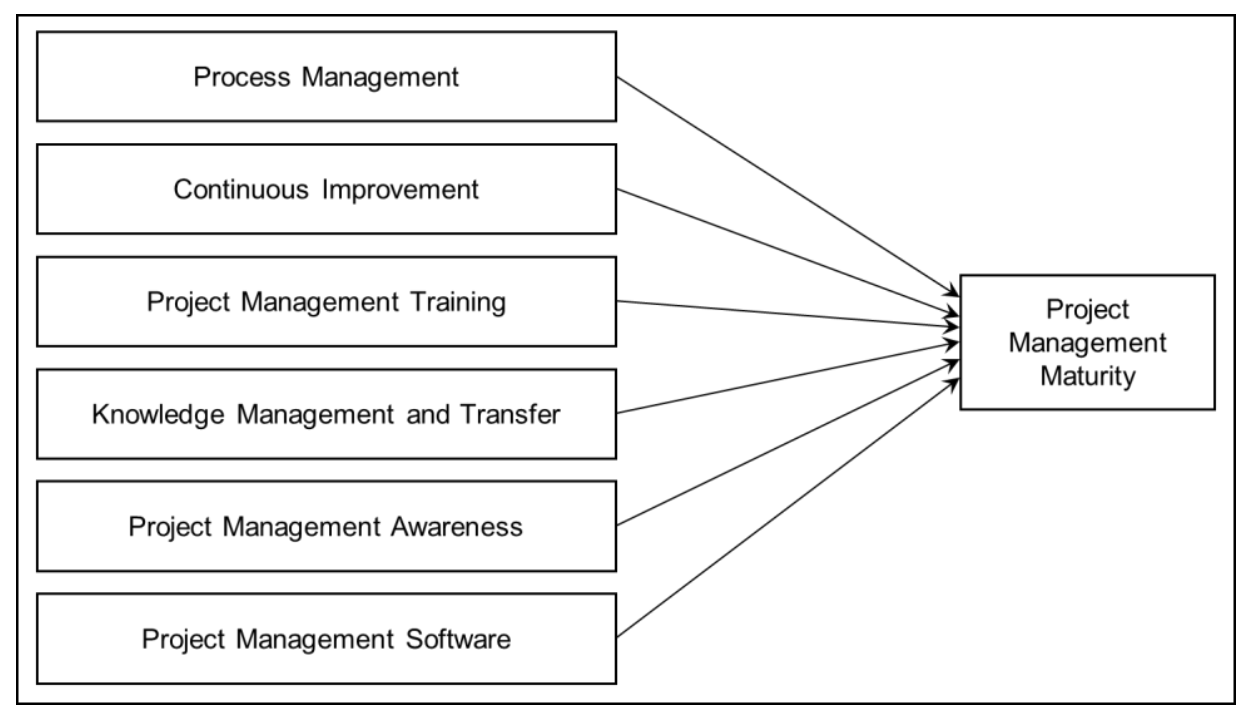

Fonte: Irfan et al. (2020, p. 73832).

Fernandes e Garcez (2019) mencionam que quanto maior a maturidade da empresa em gerenciamento de projetos, maior a vantagem competitiva gerada pelos recursos do gerenciamento de projetos. Além da vantagem competitiva, outros benefícios podem ser obtidos na adoção de práticas maduras em gerenciamento de projetos, como por exemplo, a melhoria da reputação das organizações (Irfan et al., 2020).

Ademais dos conceitos dispostos nos parágrafos supra, a maturidade do gerenciamento de projetos pode ser melhor compreendida e explicada pelos modelos de maturidade em gerenciamento de projetos (Irfan et al., 2020). Através da revisão da literatura, foi possível identificar uma ampla gama de modelos de maturidade desenvolvidos por organizações de consultoria em gerenciamento de projetos e pesquisadores (Rodrigues et al., 2006; Backlund et al. 2014; Almeida \& Neto, 2015; de Souza \& Gomes, 2015; Kwak et al., 2015; Prado, 2015; Görög, 2016; Anantatmula \& Rad, 2018; Fernandes \& Garcez, 2019; Irfan et al., 2020).

Os modelos de maturidade possuem uma ferramenta de autoavaliação que mostra e prioriza as áreas de melhoria, além de possuir um corpo de conhecimento que estabelece toda a prática necessária para a melhoria organizacional (Kwak et al., 2015). Os principais modelos de maturidade encontrados na literatura são elencados no Quadro 2. 
Quadro 2 - Quadro comparativo dos modelos de maturidade

\begin{tabular}{|c|c|c|c|c|c|c|}
\hline & CMM & КРМММ & PMMM & OPM3 & P3M3 & MMGP \\
\hline Autoria & $\begin{array}{c}\text { SEI - } \\
\text { Software } \\
\text { Engineering } \\
\text { Institute } \\
\end{array}$ & Harold Kerzner & PM Solutions & $\begin{array}{l}\text { PMI - Project } \\
\text { Management } \\
\text { Institute }\end{array}$ & $\begin{array}{c}\text { OGC - } \\
\text { Office of } \\
\text { Government } \\
\text { Commerce } \\
\end{array}$ & Darci Prado \\
\hline $\begin{array}{l}\text { Primeira } \\
\text { Publicação }\end{array}$ & 1991 & 2001 & 2002 & 2003 & 2003 & 2002 \\
\hline Orientação & Processos & Projetos & Projetos & $\begin{array}{c}\text { Projetos } \\
\text { Programas e } \\
\text { Portfólios }\end{array}$ & $\begin{array}{l}\text { Projetos, } \\
\text { Programas e } \\
\text { Portfólios }\end{array}$ & Projetos \\
\hline Dimensão & $\begin{array}{c}\text { Corporativa } \\
- \\
\text { Organizações } \\
\text { de Software e } \\
\text { Serviços de } \\
\text { Tecnologia } \\
\end{array}$ & $\begin{array}{c}\text { Corporativa - } \\
\text { Empresas } \\
\text { orientadas a } \\
\text { projetos }\end{array}$ & $\begin{array}{c}\text { Corporativa - } \\
\text { Empresas } \\
\text { orientadas a } \\
\text { projetos }\end{array}$ & $\begin{array}{c}\text { Corporativa - } \\
\text { Empresas } \\
\text { orientadas a } \\
\text { projetos }\end{array}$ & $\begin{array}{c}\text { Corporativa } \\
\text { - Empresas } \\
\text { orientadas a } \\
\text { projetos }\end{array}$ & $\begin{array}{l}\text { Corporativa } \\
\text { e Setorial - } \\
\text { Empresas } \\
\text { orientadas a } \\
\text { projetos }\end{array}$ \\
\hline $\begin{array}{l}\text { Instrumento } \\
\text { de } \\
\text { Avaliação }\end{array}$ & Checklist & Questionário & Checklist & Questionário & Questionário & Questionário \\
\hline $\begin{array}{l}\text { Abrangência } \\
\text { de Uso }\end{array}$ & Global & Global & Global & Global & Global & Nacional \\
\hline $\begin{array}{l}\text { Fonte de } \\
\text { Referência }\end{array}$ & Documento & Livro & Livro & Livro & Documento & Livro \\
\hline $\begin{array}{l}\text { Níveis de } \\
\text { Maturidade }\end{array}$ & $\begin{array}{l}5 \text { Níveis: } \\
\text { Inicial; } \\
\text { Repetido; } \\
\text { Definido; } \\
\text { Gerenciado; } \\
\text { Otimizado. }\end{array}$ & $\begin{array}{l}5 \text { Níveis: } \\
\text { Linguagem } \\
\text { Comum; } \\
\text { Processos } \\
\text { Comuns; } \\
\text { Metodologia } \\
\text { Única; } \\
\text { Benchmarking; } \\
\text { Desenvolvimento } \\
\text { Contínuo, }\end{array}$ & $\begin{array}{l}\text { 5 Níveis: } \\
\text { Processo } \\
\text { Inicial; } \\
\text { Processos } \\
\text { Estruturados; } \\
\text { Padrão } \\
\text { Organizacional; } \\
\text { Processo } \\
\text { Gerenciado; } \\
\text { Processo } \\
\text { Otimizado. }\end{array}$ & $\begin{array}{l}4 \text { Níveis: } \\
\text { Padronização; } \\
\text { Medição; } \\
\text { Controle } \\
\text { Contínuo; } \\
\text { Aprimoramento. }\end{array}$ & $\begin{array}{l}\text { 5 Níveis: } \\
\text { Processo } \\
\text { Inicial; } \\
\text { Processo } \\
\text { Repetível; } \\
\text { Processo } \\
\text { Definido; } \\
\text { Processo } \\
\text { Gerenciado; } \\
\text { Processo } \\
\text { Otimizado. }\end{array}$ & $\begin{array}{l}\text { 5 Níveis: } \\
\text { Inicial; } \\
\text { Conhecido; } \\
\text { Padronizado; } \\
\text { Gerenciado; } \\
\text { Otimizado. }\end{array}$ \\
\hline
\end{tabular}

Fonte: Adaptado de Almeida e Neto (2015), de Souza e Gomes (2015) e Kwak et al. (2015).

Na pesquisa de Souza e Gomes (2015) obteve-se como resultado que $100 \%$ das publicações acerca do modelo MMGP ocorreram no Brasil, sugerindo que este é um modelo amplamente discutido e conhecido entre os pesquisadores e praticantes nacionais. Além disso, há diversas pesquisas realizadas periodicamente com as organizações que atuam no mercado brasileiro acerca da maturidade em gerenciamento de projetos. Tais pesquisas são classificadas por tipo de organização, por regiões, categorias de projetos e demais categorias, disponíveis no endereço eletrônico (https://www.maturityresearch.com, acesso em 18/07/2020). Visto o exposto, escolheu-se pelo modelo MMGP como instrumento de coleta de dados para a organização em estudo considerando o benchmarking deste instrumento no mercado o qual a empresa está inserida.

O modelo proposto por Prado (2015) apresenta cinco níveis de maturidade de uma organização: inicial; conhecido; padronizado; 
gerenciado e; otimizado. Cada um dos cinco níveis de maturidade em gerenciamento de projetos apresenta sete dimensões da maturidade: alinhamento estratégico; uso da estrutura organizacional conveniente; informatização; uso de metodologia; competência comportamental; competência em aspectos técnicos e contextuais, e; competência em gerenciamento de projetos e programas. $\mathrm{O}$ nível 1 é o mais baixo e o nível 5 o mais alto. $\mathrm{O}$ modelo ilustrado na Figura 2 tem o seguinte entendimento acerca dos níveis de maturidade:

- Nível 1 (Inicial) - Não há um entendimento ou percepção sobre projetos e gerenciamento de projetos por parte da organização. Os projetos são feitos através de "boa vontade";

- Nível 2 (Conhecido) - Já há o uso de procedimentos básicos para o gerenciamento dos projetos da organização, no entanto, de maneira isolada e sem padronização;

- Nível 3 (Padronizado) - Há por parte da organização procedimentos padronizados de gerenciamento de projetos e evolução das competências. Os projetos são planejados e seu desempenho é medido;

- Nível 4 (Gerenciado) - O nível de competência da organização em gerenciar os projetos já é alto e possui uma quantidade alta de projetos concluídos e com desempenho medidos;

- Nível 5 (Otimizado) - A organização já apresenta uma plataforma de gerenciamento de projetos funcionando e entregando resultados, além disso, investe na melhoria contínua de seus processos.

Figura 2 - Modelo de Maturidade MMGP adaptado de Prado (2015)

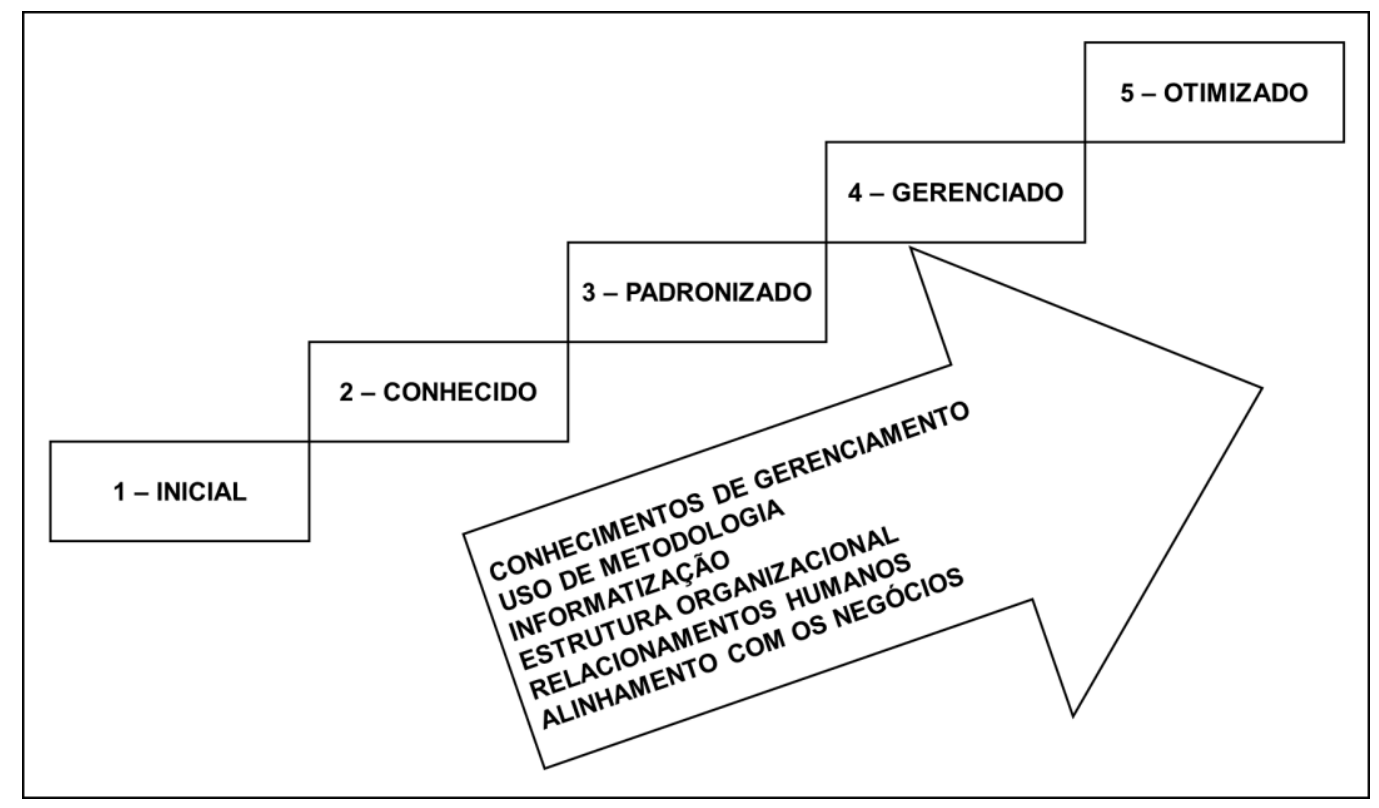

Fonte: Adaptado de Maturity Research (2020). 
Ainda segundo Prado (2015), o nível de maturidade em gerenciamento de projetos possui relação direta com o percentual de sucesso dos projetos de uma organização conforme ilustra a Figura 3.

Figura 3 - Relação esperada entre Maturidade e Sucesso adaptado de Prado (2015)

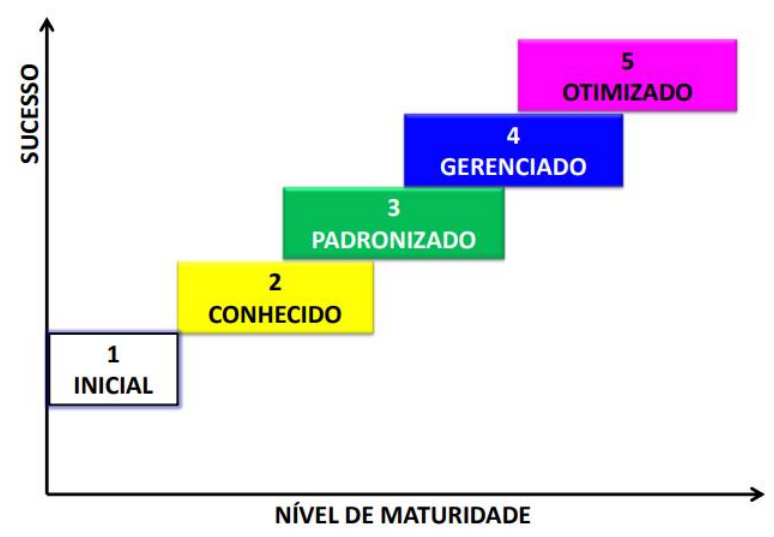

Fonte: Adaptado de Maturity Research (2020).

Conforme mostrado na revisão de literatura, existe uma ampla gama de modelos de maturidade concentrados na melhoria de processos individuais (modelos de maturidade de capacidade) e grupos de processos (modelos de maturidade de gerenciamento de processos organizacionais) de uma empresa (Kwak et al., 2015). Desta forma, os modelos de maturidade propostos têm o potencial de contribuir para alcançar maiores taxas de sucesso no decurso da implantação de projetos únicos e de programas de projetos nas organizações (Görög, 2016).

\subsection{Escritório de gerenciamento de projetos e a maturidade em gerenciamento de projetos}

Para reduzir a ineficiência técnica, várias abordagens de como melhorar os processos e elevar a maturidade do gerenciamento de portfólio de projetos, realinhar a estrutura da organização ou fortalecer o alinhamento estratégico com as metas de negócios são recomendadas aos EGPs (Ko \& Kim, 2019). O gerenciamento de portfólio é uma função importante do EGP de uma organização e a maturidade do gerenciamento de projetos provavelmente resultará dos seus esforços (Anantamula \& Rad, 2018).

De acordo com Aubry (2015), o papel do EGP como uma área de suporte a projetos tem efeito positivo direto na performance do gerenciamento de projetos, na maturidade do gerenciamento de projetos e na performance dos negócios. Os objetivos do EGP em um contexto pluralista, o nível de maturidade e a cultura da organização, as características específicas do projeto e outras variáveis contextuais provavelmente terão um efeito 
moderador na criação de valor do EGP (OtraAho et al., 2019).

O estudo de Andersen et al. (2006) propôs um ciclo de vida para EGPs desde sua concepção até sua plena operação, baseado em três etapas: I) Desenvolvimento de abordagens e ferramentas comuns para gerenciamento de projetos; II) Introdução de processos de governança e garantia da qualidade e; III) Implementação do verdadeiro gerenciamento de portfólio de projetos. Segundo os autores supracitados, à medida que o EGP avança pelas fases, a sua maturidade aumenta assim como a da organização como um todo, mudando o foco do EGP, respectivamente: I) Suporte a projetos individuais; II) Suporte aos proprietários de projetos individuais e; III) Suporte ao portfólio de projetos acumulados e à alta administração. Este ciclo é representado pela Figura 4.

Figura 4 - Ciclo de vida de um EGP por Andersen et al. (2006)

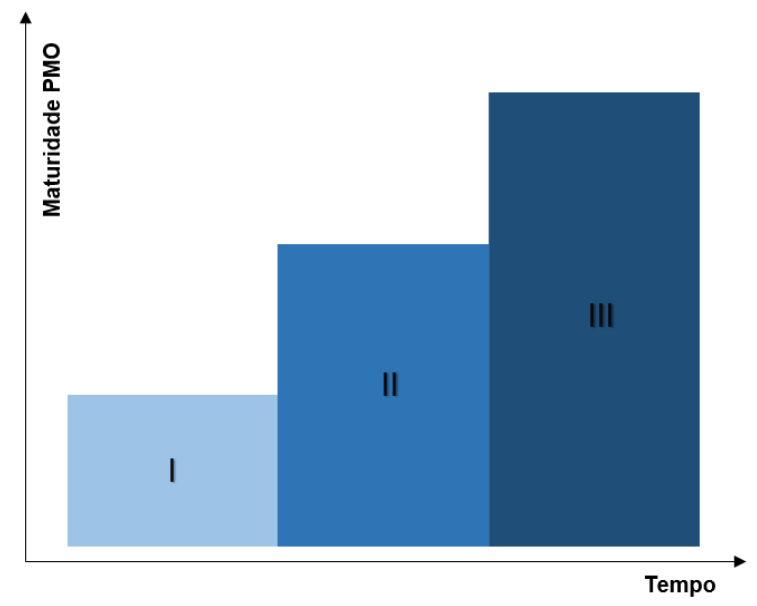

Fonte: Adaptado de Andersen et al. (2006).

O caminho para a maturidade do EGP começa com o estabelecimento da capacidade de criar valor para os clientes e para toda a empresa; isso é seguido pela implementação e aplicação dessas práticas em todos os níveis e ramos da organização (Khalema, Van Waveren, \& Chan, 2015).

Segundo Szalay et al. (2017), a avaliação do nível de maturidade de um EGP considera o grau de sofisticação com que ele desempenha cada uma de suas funções, além de levar em consideração os interesses de seus stakeholders e as necessidades da organização. Para Otra-aho et al. (2019), EGPs que podem renovar suas funções e processos em resposta às mudanças no ambiente de negócios, aumentarão sua probabilidade de sucesso.

Jalal \& Koosha (2015) mencionam que a realização dos objetivos atrelados ao sucesso da performance do gerenciamento de projetos e dos projetos, depende muito do desempenho e da maturidade do EGP. Quanto mais os escritórios de gerenciamento de projetos alcançarem níveis maiores de capacidade e 
maturidade, maior será o alcance desses objetivos.

Portanto, a maturidade do EGP agrega valor ao gerenciamento de projetos no âmbito organizacional. Estudando a correlação entre a maturidade do EGP e a maturidade do gerenciamento de projetos da organização, presume-se que o desempenho do projeto seja diretamente realizável a partir de níveis mais altos de maturidade da empresa (Khalema et al., 2015).

\section{Metodologia da pesquisa}

Nesta seção são apresentados os instrumentos utilizados para coleta e análise de dados baseados na literatura. Os métodos são adotados para investigar o nível de maturidade em gerenciamento de projetos da organização a fim de responder à questão central da pesquisa.

\subsection{Coleta de dados}

Primeiramente realizou-se a coleta de dados por meio de uma pesquisa bibliográfica para as fontes secundárias. Os dados foram obtidos através de um levantamento bibliométrico utilizando as palavras-chave dispostas neste trabalho.

Tendo em vista o reconhecimento das distintas formas de avaliação do nível de maturidade em gerenciamento de projetos durante a revisão da literatura, o presente estudo apoia-se na aplicação do modelo de avaliação MMGP de Darci Prado (Prado, 2015). O MMGP foi considerado para o presente estudo por se tratar de um modelo amplamente adotado no mercado brasileiro de acordo com de Souza e Gomes (2015).

De forma complementar ao MMGP e com objetivo de explorar qualitativamente a discussão acerca do nível de maturidade da empresa, adotou-se um roteiro de entrevista semiestruturada. O questionário denominado Questionário Complementar foi elaborado buscando endereçar as áreas de conhecimento centrais do PMI (2017) no gerenciamento de projetos que são vistas como mais usuais e mais críticas na empresa. $\mathrm{O}$ roteiro elaborado contemplou perguntas referentes às seguintes áreas de conhecimento conforme PMI (2017): escopo, cronograma, integração, recursos humanos, comunicação, stakeholders e riscos.

Além dos instrumentos mencionados, foi utilizado o resultado de uma pesquisa documental realizada na organização no segundo semestre de 2018, que teve como objetivo investigar os principais aspectos de falhas no gerenciamento dos projetos da organização que impactaram as respectivas performances nos últimos 06 (seis) anos.

\subsection{Caracterização do objeto e dos respondentes do estudo}

O objeto de estudo é uma empresa de pequeno porte, com capital $100 \%$ nacional. Sua atuação se dá no campo de consultoria em projetos de engenharia multidisciplinar para as áreas de civil, mecânica, elétrica e instrumentação. Os seus clientes principais são empresas de médio e grande porte dos setores de óleo e gás, petroquímicos, lubrificantes e biocombustíveis. A empresa possui estrutura 
organizacional "projetizada" com 30 funcionários, sendo: 02 diretores; 08 gerentes de projetos; 14 analistas (projetistas, desenhistas e técnicos) e; 06 em departamentos auxiliares (informática, arquivo técnico e recursos humanos). No que concerne à natureza dos projetos desenvolvidos, os mesmos variam desde estudos para elaboração de orçamentos para investimentos (projetos básicos) até projetos para construção (projetos executivos).
Em relação aos respondentes, tratamse de 08 (oito) profissionais com experiência em gerenciamento de projetos e que possuem contato direto com os projetos da empresa. Esses respondentes foram designados visto o tempo de atuação na empresa e suas experiências na condução dos projetos. $\mathrm{O}$ Quadro 3 sumariza o perfil dos respondentes.

Quadro 3 - Perfil dos respondentes

\begin{tabular}{|c|c|c|}
\hline $\begin{array}{l}\text { Grupo de } \\
\text { respondente }\end{array}$ & $\begin{array}{c}\text { Identificaçã } \\
\quad \text { o }\end{array}$ & Perfil \\
\hline \multirow[b]{2}{*}{ Diretoria } & Diretor 01 & $\begin{array}{l}\text { Engenheiro Mecânico, com } 39 \text { anos de formação e atuação na área de } \\
\text { projetos de óleo e gás, atua na diretoria há } 26 \text { anos; }\end{array}$ \\
\hline & Diretor 02 & $\begin{array}{l}\text { Engenheiro Mecânico, } 52 \text { anos de formação e atuação na área de } \\
\text { projetos de óleo e gás, atua na diretoria há } 26 \text { anos, como sócio } \\
\text { fundador. }\end{array}$ \\
\hline \multirow{8}{*}{$\begin{array}{l}\text { Gerentes de } \\
\text { Projeto }\end{array}$} & GP 01 & $\begin{array}{l}\text { Engenheiro Eletricista, com } 17 \text { anos de formação e atuação na área de } \\
\text { projetos de óleo e gás e indústria. Atua como gerente de projetos há } \\
12 \text { anos; }\end{array}$ \\
\hline & GP 02 & $\begin{array}{l}\text { Engenheiro Eletricista, } 7 \text { anos de formação e total de } 13 \text { anos de } \\
\text { atuação na área de óleo e gás e indústria. Atua como gerente de } \\
\text { projetos há dois anos; }\end{array}$ \\
\hline & GP 03 & $\begin{array}{l}\text { Engenheiro Civil, } 45 \text { anos de formação e atuação, nas áreas de } \\
\text { construção civil, óleo e gás e indústria. Atua como gerente de projetos } \\
\text { há } 30 \text { anos. }\end{array}$ \\
\hline & GP 04 & $\begin{array}{l}\text { Engenheiro Químico, } 10 \text { anos de formação e atuação na área de } \\
\text { projetos de óleo e gás. Atua como gerente de projetos há } 5 \text { anos. }\end{array}$ \\
\hline & GP 05 & $\begin{array}{l}\text { Engenheira Química, } 9 \text { anos de formação e atuação na área de } \\
\text { projetos de óleo e gás. Atua como gerente de projetos há } 3 \text { anos. }\end{array}$ \\
\hline & GP 06 & $\begin{array}{l}\text { Engenheiro Químico, } 6 \text { anos de formação e atuação na área de } \\
\text { projetos de óleo e gás. Atua como gerente de projetos há } 3 \text { anos. }\end{array}$ \\
\hline & GP 07 & $\begin{array}{l}\text { Engenheiro Químico, } 10 \text { anos de formação e atuação na área de } \\
\text { projetos de óleo e gás. Atua como gerente de projetos há } 4 \text { anos. }\end{array}$ \\
\hline & GP 08 & $\begin{array}{l}\text { Engenheiro Químico, } 10 \text { anos de formação e atuação na área de } \\
\text { projetos de óleo e gás. Atua como gerente de projetos há } 5 \text { anos. }\end{array}$ \\
\hline
\end{tabular}

Fonte: Elaborado pelos autores.

A aplicação dos dois tipos de instrumentos foi feita de maneira distinta. $\mathrm{O}$ instrumento de avaliação do MMGP foi aplicado por grupo, sendo o primeiro grupo composto pelos gerentes de projetos enquanto o segundo grupo pela diretoria, ao passo que o 
Questionário Complementar foi aplicado de forma individual apenas com os gerentes de projetos, por se tratar de um formulário de aplicação prática quanto aos processos de gerenciamento de projetos.

\subsection{Avaliação $M M G P$}

A avaliação MMGP é iniciada durante a aplicação do questionário com os grupos supracitados de forma presencial. Após a obtenção das respostas de $100 \%$ dos respondentes pretendidos (02 diretores e 08 gerentes de projeto), os dados são analisados por meio da atribuição de graus às perguntas objetivas que descrevem o nível de maturidade da empresa, em aderência ao MMGP (Prado, 2015).

Para cada pergunta existem seis alternativas de resposta. A forma de contabilização em cada questão do instrumento MMGP é feita através do critério onde: Resposta (a) vale 10 pontos; Resposta (b) vale 7 pontos; Resposta (c) vale 4 pontos; Resposta (d) vale 2 pontos e; Resposta (e) vale 0 pontos.

A partir das pontuações obtidas no questionário é possível, pela soma da pontuação em cada nível, traçar o perfil de aderência. Sendo esse perfil representado pelo Quadro 4.

Quadro 4 - Perfil de Aderência

\begin{tabular}{|c|c|c|c|c|c|c|c|c|c|c|c|}
\hline \multirow{2}{*}{ Nível } & Pontos & \multicolumn{9}{|c|}{ Perfil de Aderência } \\
\cline { 4 - 12 } & Obtidos & $\mathbf{1 0}$ & $\mathbf{2 0}$ & $\mathbf{3 0}$ & $\mathbf{4 0}$ & $\mathbf{5 0}$ & $\mathbf{6 0}$ & $\mathbf{7 0}$ & $\mathbf{8 0}$ & $\mathbf{9 0}$ & $\mathbf{1 0 0}$ \\
\hline $\mathbf{2}$ & & & & & & & & & & & \\
\hline 3 & & & & & & & & & & & \\
\hline $\mathbf{4}$ & & & & & & & & & & & \\
\hline 5 & & & & & & & & & & & \\
\hline
\end{tabular}

Fonte: Elaborado pelos autores.

Para a composição do Quadro 4 são contabilizados o total de pontos em cada nível, traçando-se uma reta em cada linha (nível) até a correspondente coluna (pontuação atingida). $\mathrm{Na}$ análise das respostas de cada nível, é possível também obter o resultado de aderência por área no Quadro 5. O referido quadro permite a visualização do percentual de aderência em áreas estipuladas pelo próprio MMGP, e seu preenchimento é feito através do próprio site da instituição (http://www.maturityresearch.com/novosite/in dex.html), após o cadastro e o fornecimento dos dados da empresa avaliada bem como das respostas de cada uma das questões do modelo MMGP. 
Quadro 5 - Aderência por área

\begin{tabular}{|c|c|c|c|c|c|c|c|c|c|c|c|}
\hline & \multirow{2}{*}{$\%$} & \multicolumn{9}{|c|}{ Aderência (\%) } & $\mathbf{7 0}$ \\
\hline & & $\mathbf{1 0}$ & $\mathbf{2 0}$ & $\mathbf{3 0}$ & $\mathbf{4 0}$ & $\mathbf{5 0}$ & $\mathbf{6 0}$ & $\mathbf{7 0}$ & $\mathbf{8 0}$ & $\mathbf{9 0}$ \\
\hline Comp. em Ger. de Projetos & & & & & & & & & & & \\
\hline Comp. Técnica e Contextual & & & & & & & & & & & \\
\hline Comp. Comportamental & & & & & & & & & & & \\
\hline Metodologia & & & & & & & & & & & \\
\hline Informatização & & & & & & & & & & & \\
\hline Alinhamento Estratégico & & & & & & & & & & & \\
\hline Estrutura Organizacional & & & & & & & & & & & \\
\hline
\end{tabular}

Fonte: Elaborado pelos autores.

Para o resultado final da pontuação que indicará o nível de maturidade da empresa, é necessário a aplicação da seguinte fórmula (equação 1).

$$
\text { Avaliação final }=\frac{(100+\text { total_de_pontos })}{100}
$$

Ao final da aplicação do instrumento de análise do MMPG, podem ser obtidos três resultados: perfil de aderência por nível avaliado, aderência percentual por área e pontuação total do nível de maturidade.

\section{Análise e discussão dos resultados}

Os resultados advindos da aplicação dos instrumentos mencionados na metodologia são discutidos nesta seção. Além dos dados obtidos na investigação empírica, a análise e discussão dos resultados é apoiada pela fundamentação teórica apresentada na seção 2 deste trabalho.

\subsection{Análise do nível de maturidade - avaliação do grupo 1 (diretores)}

A primeira resultante da aplicação do formulário com o grupo de diretores é o Quadro 6, onde foram concentradas as pontuações totais em cada um dos níveis, sinalizando a aderência da empresa por nível.

Quadro 6 - Perfil de Aderência - Diretores

\begin{tabular}{|c|c|c|c|c|c|c|c|c|c|c|c|}
\hline \multirow{2}{*}{ Nível } & \multirow{2}{*}{$\begin{array}{l}\text { Pontos } \\
\text { Obtidos }\end{array}$} & \multicolumn{10}{|c|}{ Perfil de Aderência } \\
\hline & & 10 & 20 & 30 & 40 & 50 & 60 & 70 & 80 & 90 & 100 \\
\hline 2 & 34 & 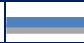 & & 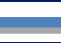 & & & & & & & \\
\hline 3 & 21 & 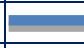 & 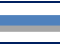 & & & & & & & & \\
\hline 4 & 20 & 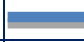 & 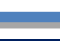 & & & & & & & & \\
\hline 5 & 0 & & & & & & & & & & \\
\hline
\end{tabular}

Fonte: Elaborado pelos autores.

Como observado no Quadro 6, segundo a avalição submetida aos diretores, a empresa possui maior aderência ao nível
"Conhecido" do modelo MMPG, o que denota que suas práticas ainda se encontram em estágios introdutórios, com iniciativas isoladas 
no controle de seus projetos, sem o estabelecimento de uma plataforma padronizada. Nos níveis "Padronizado" e "Gerenciado", os respondentes obtiveram pontuações inferiores ao nível "Conhecido".

A segunda resultante da aplicação do instrumento é apresentada no Quadro 7, onde é evidenciada a aderência percentual por área, sendo cada uma dessas áreas estabelecidas pelo próprio MMGP em seu site, com preenchimento realizado diretamente no site da instituição.

Quadro 7 - Aderência por área - Diretores

\begin{tabular}{|c|c|c|c|c|c|c|c|c|c|c|c|}
\hline \multirow{2}{*}{ Dimensão } & \multirow{2}{*}{$\%$} & \multicolumn{10}{|c|}{ Aderência (\%) } \\
\hline & & 10 & 20 & 30 & 40 & 50 & 60 & 70 & 80 & 90 & 100 \\
\hline Comp. em Ger. de Projetos & 20 & & & & & & & & & & \\
\hline Comp. Técnica e Contextual & 19 & 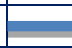 & 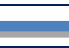 & & & & & & & & \\
\hline Comp. Comportamental & 16 & & $=$ & & & & & & & & \\
\hline Metodologia & 21 & & & 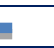 & & & & & & & \\
\hline Informatização & 23 & & & 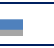 & & & & & & & \\
\hline Alinhamento Estratégico & 19 & & 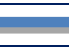 & & & & & & & & \\
\hline Estrutura Organizacional & 14 & 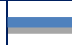 & 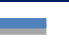 & & & & & & & & \\
\hline
\end{tabular}

Fonte: Elaborado pelos autores.

Percebe-se a partir do Quadro 7, que o maior percentual está atribuído à área de informatização, seguidas das áreas de metodologia e competência em gerenciamento de projetos. A terceira e última resultante, o nível de maturidade da empresa obtido a partir da aplicação da Equação I apresentada na seção de metodologia foi de nível 1,75 (75 pontos). Tal dado representa que a empresa está classificada entre os níveis 1 e 2 segundo
Prado (2015), apresentando uma maior proximidade com o nível "Conhecido" do MMGP.

\subsection{Análise do nível de maturidade - avaliação do grupo 2 (gerentes)}

A primeira resultante da aplicação do formulário com o grupo de gerentes de projetos é apresentada no Quadro 8.

Quadro 8 - Perfil de Aderência - Gerentes de Projetos

\begin{tabular}{|c|c|c|c|c|c|c|c|c|c|c|c|}
\hline \multirow{2}{*}{ Nível } & \multirow{2}{*}{$\begin{array}{l}\text { Pontos } \\
\text { Obtidos }\end{array}$} & \multicolumn{10}{|c|}{ Perfil de Aderência } \\
\hline & & 10 & 20 & 30 & 40 & 50 & 60 & 70 & 80 & 90 & 100 \\
\hline 2 & 20 & - & 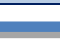 & & & & & & & & \\
\hline 3 & 8 & 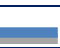 & & & & & & & & & \\
\hline 4 & 4 & 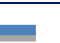 & & & & & & & & & \\
\hline 5 & 0 & & & & & & & & & & \\
\hline
\end{tabular}

Fonte: Elaborado pelos autores. 
A avaliação feita a partir dos gerentes indica maior aderência ao nível "Conhecido", seguidas dos níveis "Padronizado" e "Gerenciado" com pontuações menores, destoando de forma significativa da percepção dos diretores para os mesmos níveis.

A segunda resultante da aplicação do formulário no grupo de gerentes é mostrada no Quadro 9.

Quadro 9 - Aderência por área - Gerentes de Projetos

\begin{tabular}{|c|c|c|c|c|c|c|c|c|c|c|c|}
\hline \multirow{2}{*}{ Dimensão } & \multirow{2}{*}{$\%$} & \multicolumn{10}{|c|}{ Aderência (\%) } \\
\hline & & 10 & 20 & 30 & 40 & 50 & 60 & 70 & 80 & 90 & 100 \\
\hline Comp. em Ger. de Projetos & 10 & & & & & & & & & & \\
\hline Comp. Técnica e Contextual & 6 & 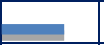 & & & & & & & & & \\
\hline Comp. Comportamental & 6 & 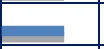 & & & & & & & & & \\
\hline Metodologia & 10 & & & & & & & & & & \\
\hline Informatização & 9 & 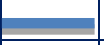 & & & & & & & & & \\
\hline Alinhamento Estratégico & 11 & 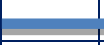 & & & & & & & & & \\
\hline Estrutura Organizacional & 8 & $\square$ & & & & & & & & & \\
\hline
\end{tabular}

Fonte: Elaborado pelos autores.

Neste quadro, percebe-se que o maior percentual está atribuído à área de alinhamento estratégico, seguidas das áreas de metodologia e competência em gerenciamento de projetos, no entanto, assim como no Quadro 8, esses resultados percentuais destoam da percepção dos diretores. A resultante final apresenta o nível de maturidade da empresa com nível 1,32 (32 pontos). Tal dado representa que a empresa está classificada entre os níveis 1 e 2 segundo Prado (2015), apresentando uma maior proximidade com o nível "Inicial” do MMGP.

\subsection{Análise comparativa entre os grupos de respondentes}

Tomando por base os dois resultados, é possível a elaboração de um comparativo entre a percepção da diretoria e a dos gerentes de projetos. Para o resultado do nível de maturidade obtido, considerando esta escala variando de 1 a 4, o comparativo das duas avaliações mostra um GAP de $-0,43(=1,32$ 1,75), representando $32,58 \%$ de distorção perceptual. A distorção perceptual representa as visões distintas dos gerentes de projetos e dos diretores da organização que resultaram nos níveis "Inicial" e "Conhecido" respectivamente, acerca do nível de maturidade.

A partir dos quadros de aderência por área obtidos nas avaliações dos dois grupos, (Quadros 7 e 9), pôde-se traçar o gráfico radar ilustrado na Figura 5, evidenciando os distanciamentos perceptuais entre os grupos respondentes. 
Figura 5 - Percepção da maturidade em gerenciamento

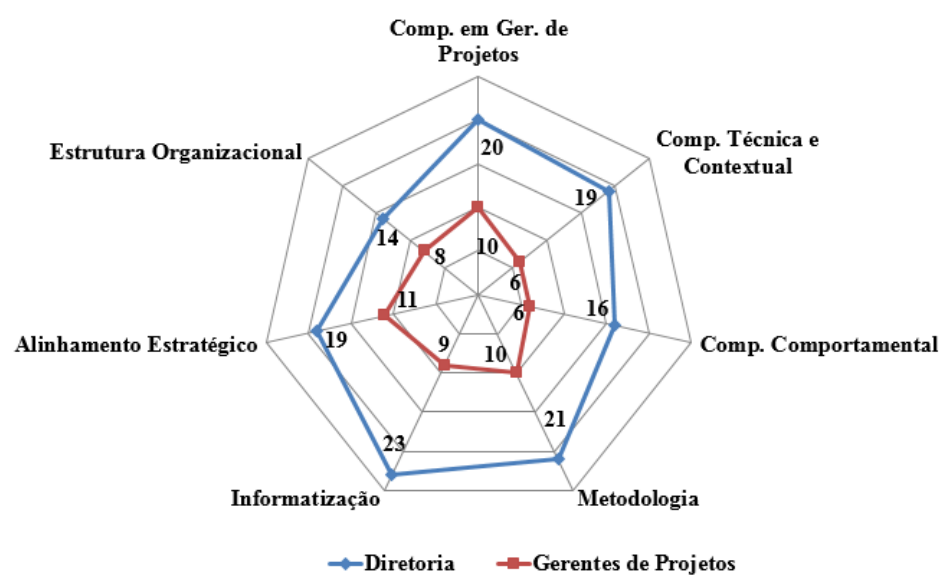

Fonte: Elaborado pelos autores.

As temáticas com o maior distanciamento de percepção foram informatização, competências técnica e contextual e metodologia. As distâncias perceptuais entre os dois grupos avaliados indicam uma falta de alinhamento ao que concerne o uso de boas práticas em gerenciamento de projetos, incluindo sistemas, ferramentas e/ou possibilidades de inovação além da qualificação e conhecimento acerca dos conceitos fundamentais para o bom gerenciamento dos projetos. Tal distanciamento reforça o resultado de um nível ainda inicial de maturidade em gerenciamento de projetos.

\subsection{Análise do questionário complementar}

O questionário complementar foi aplicado a cada um dos gerentes de projetos de forma presencial e individual. Além disso, durante as entrevistas, foram observadas as percepções dos gerentes sobre o assunto gerenciamento de projetos com base nos conceitos estabelecidos pelo PMI (2017). Os resultados são indicados nos parágrafos infra.

Dentre os respondentes, 06 dos 10 entrevistados nem sempre recebem e 04 nunca receberam um documento de escopo descrevendo quais são as entregas, premissas e restrições do projeto. $\mathrm{Na}$ percepção dos gerentes de projetos, a maior dificuldade no desenvolvimento de projetos na organização está ligada à falta de um documento claro de escopo (04 entrevistados); sendo seguido pela falta de documentos, metodologias e processos padronizados (03 entrevistados); horas mal dimensionadas (02 entrevistados) e; falta de integração entre as áreas do projeto (01 entrevistado).

Em relação ao cronograma dos projetos, 07 entrevistados desenvolveram projetos que não tiveram sua "baseline" de tempo alterada quando houve qualquer solicitação de alteração de escopo por parte do cliente. Na percepção dos gerentes, o maior 
motivo de atraso nas entregas está relacionado às alterações no escopo e o segundo maior motivo está atrelado às horas mal estimadas

Em relação à comunicação com os clientes, metade dos gerentes da organização acredita que um canal de comunicação que promova uma melhor integração interna e também com os clientes, pode melhorar o apoio no desenvolvimento dos projetos. Dos 10 gerentes de projeto, 06 sempre comunicam os clientes sobre os impactos da alteração de escopo. Já internamente, todos os gerentes apontaram para falta de avaliações e feedbacks periódicos, assim como a falta de treinamento e incentivo para o aumento da qualificação tanto dos gerentes, quanto das equipes dos projetos.

Todos os gerentes relataram que as solicitações de alteração dos documentos do projeto (por parte dos clientes) é solicitada apenas por e-mail, sem a apresentação de uma ordem de variação documentada através de registros. Apenas 03 dos 10 gerentes sempre documentam as solicitações e mudanças dos projetos.

Quanto à gestão da qualidade dos projetos, apenas 01 dos gerentes entrevistados utiliza ferramentas para avaliação da qualidade dos projetos desenvolvidos enquanto nenhum dos gerentes faz o registro das lições aprendidas nos seus projetos.

Os gerentes acreditam que o assunto gerenciamento de projetos é pouco explorado pela organização. Segundo eles, o gerenciamento do escopo nos projetos é o item mais sensível das 10 áreas de conhecimento segundo PMI (2017), sendo este o que traz o maior impacto e que apresenta mais falhas na organização para 06 dos 10 respondentes.

De acordo com o respondente 06 , os prazos impostos pelos clientes para a entrega dos projetos são muito estreitos, sendo que o ambiente dinâmico da empresa condiciona à gerência de dois ou mais projetos ao mesmo tempo. Tal percepção é expressa pela fala a seguir:

Uma das grandes dificuldades em atender os prazos estabelecidos pelos clientes, além da má definição do escopo devido às mudanças constantes, é lidar com mais de um projeto ao mesmo tempo. Todos eles têm prazos curtíssimos e com clientes que possuem requisitos completamente diferentes. Fica muito difícil atender ao cronograma com poucos recursos e tendo que dividir os recursos desta maneira.

A padronização de documentos, processos e metodologia para desenvolver projetos ainda é insuficiente e acontece de forma isolada, não sendo parte da cultura organizacional, com apenas parte dos gerentes buscando padronizar o que está ligado aos seus próprios projetos. A definição de ferramentas para avaliação da qualidade das entregas do projeto é quase nula, tendo apenas o respondente 08 indicado o uso de alguma metodologia:

[...] acho importante que haja uma avaliação da qualidade do trabalho apresentado principalmente para que possamos ter a percepção daquilo que estamos entregando para o cliente $\mathrm{e}$ 
também para aprimorar as práticas internas.

O registro de lições aprendidas foi um dos itens que gerou maior envolvimento nas pesquisas e foi o mais receptivo por parte dos entrevistados, sendo apontado como um dos que mais beneficiaria os futuros projetos. Tal afirmação é sustentada pelo argumento do respondente 02 :

No pouco tempo que estou na função pude perceber poucas iniciativas aqui dentro. Poderíamos fazer muitos brainstormings antes do início dos projetos, coletar registros formais das atividades que deram certo e errado nos projetos, avaliar o desempenho de cada um deles com critérios e outras coisas mais. Porém os prazos são sempre tão curtos e sempre temos que trabalhar para as entregas que acabamos não dando o devido valor. Mas com certeza seria uma boa oportunidade de agregar conhecimento.

Os entrevistados em sua totalidade demonstram insatisfação quanto aos treinamentos, incentivos, avaliações e feedbacks periódicos. Todos apontaram a necessidade do gerenciamento de recursos humanos (pessoas) não como uma via para aumentos salariais apenas, mas para o desenvolvimento pessoal e profissional.

\subsection{Discussão dos resultados}

No âmbito da pesquisa de identificação de práticas no gerenciamento de projetos realizada com os gerentes, ficou evidente que: de forma isolada, alguns gerentes de projetos possuem conhecimentos introdutórios em gerenciamento de projetos; alguns fazem o uso (básico) de ferramentas (softwares de gerenciamento) para sequenciamento de atividades e; que existem iniciativas isoladas, dado que não existe uma plataforma (métodos, processos, ferramentas, etc) padrão para gerenciar os projetos. Já no âmbito da avaliação do nível maturidade, foi evidenciado um distanciamento perceptual quanto ao nível de maturidade organizacional no campo do gerenciamento de projetos. Apesar das percepções distintas, ambos resultados finais demonstraram um nível de maturidade baixíssimo na organização que oscila entre o "Inicial" e "Conhecido" de acordo com cada grupo.

Segundo Anantatmula e Rad (2018), o Project Management Institute (PMI) acredita firmemente que o EGP é um dos caminhos para alcançar o sucesso de projetos e da maturidade em gerenciamento de projetos (Anantatmula \& Rad, 2018). Para Jerbrant (2014) uma das maneiras mais comuns de iniciar e enfatizar a estrutura e o planejamento em uma organização baseada em projetos é estabelecer um EGP.

Com base na revisão da literatura, onde foram evidenciados o papel, os benefícios e os campos de atuação de um EGP, nas investigações realizadas na organização quanto à sua maturidade em gerenciamento de projetos e a aderência às boas práticas conforme PMI (2017), sugere-se aqui a implantação de um EGP na empresa em estudo.

Nesse ínterim, o EGP proposto deve atender as necessidades de padronização dos 
processos, metodologias e documentos, e fornecer a capacitação ao corpo técnico de projetos, de forma que cada etapa de sua atuação esteja alinhada e legitimada pela alta administração (diretoria) da empresa.

O EGP é responsável por orientar o gerenciamento dos projetos aos objetivos organizacionais através de uma variedade de ferramentas de governança do conhecimento para conectar projetos à organização e facilitar o compartilhamento de conhecimento entre eles (Too \& Weaver, 2014; Sergeeva \& Ali, 2020). Neste princípio, o tipo de atuação do EGP proposto para a organização é o de desenvolvimento de competências em gerenciamento de projetos (Desouza \& Evaristo, 2006; Hobbs \& Aubry, 2007; Too \& Weaver, 2014; Jalal \& Koosha, 2015; Anantatmula \& Rad, 2018; Sergeeva \& Ali, 2020). Esta atuação foi definida de acordo com o nível de maturidade em gerenciamento de projetos apresentado pela organização e o que preconiza a literatura.

Visto a função dos gerentes de projetos em focar nas entregas e a função do EGP em se concentrar nos processos organizacionais, governança e melhores práticas (Sergeeva \& Ali, 2020), o objetivo do EGP proposto é capacitar os gerentes e equipe de projetos, através de treinamentos, criação e uso de metodologias, padronização de processos e suporte aos novos projetos da organização, bem como alinhar a estrutura de governança dos projetos à estratégia organizacional.

Este trabalho apresenta uma proposta para a implantação de um EGP na organização em estudo com as características mencionadas anteriormente. A implantação do mesmo se dará com a estrutura de um projeto corporativo interno, onde serão indicadas e definidas todas as etapas e entregáveis de sua implantação. Além da descrição de cada etapa e entregáveis, serão apontados os principais fatores de influência para a implantação do EGP considerando o problema de pesquisa, as características da organização e o que preconiza a literatura. Dessa forma a Figura 6 apresenta as propostas das etapas e entregas. 
Figura 6 - EAP de implantação EGP

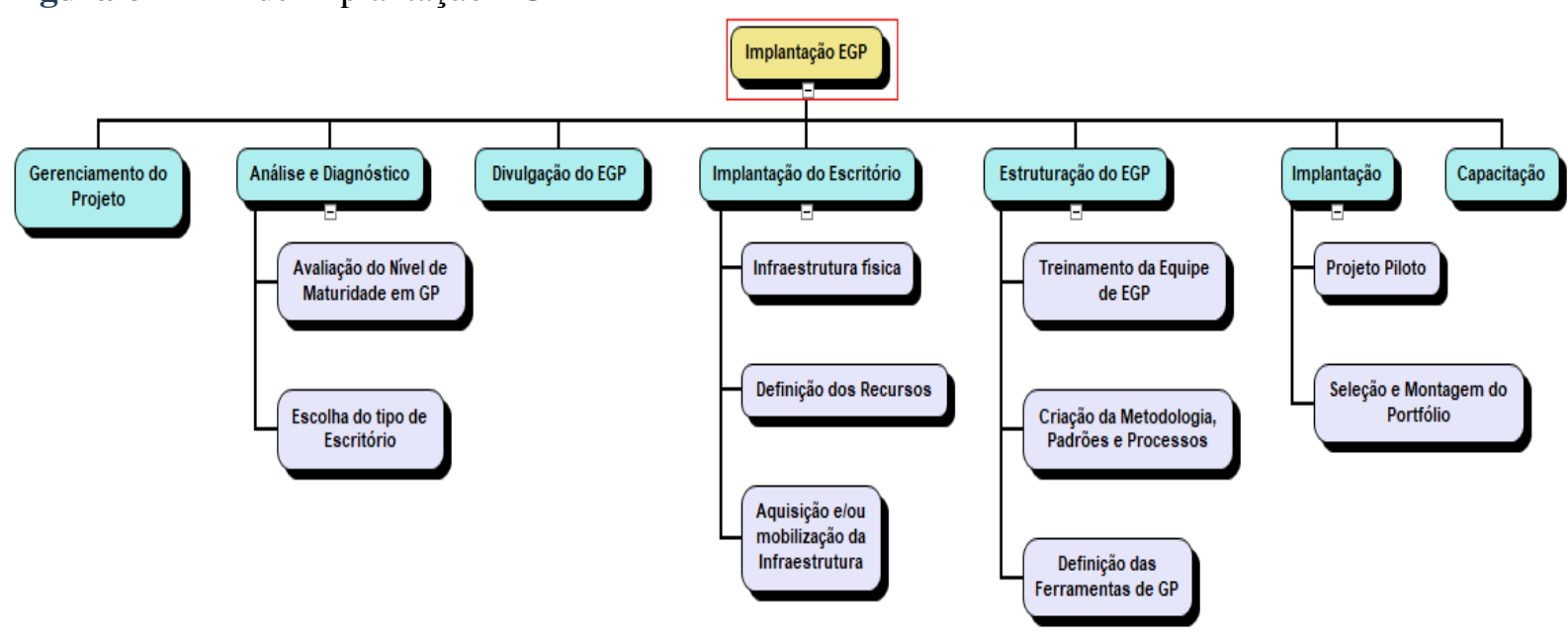

Fonte: Elaborado pelos autores.

A visão macro de cada grupo de entrega (e também marcos) propostos na Figura 6 é definida a seguir:

- Gerenciamento do projeto: consiste na etapa de planejamento do projeto, envolvendo os planos de projetos das áreas de conhecimento e as definições de como será feito o controle do projeto de implantação do EGP;

- Análise e diagnóstico: Esta avaliação foi realizada nesta pesquisa através da análise do nível de maturidade da organização segundo Prado (2015) e dos formulários, entrevistas com os gerentes e a diretoria como já mostrado na metodologia. A partir deste ponto de compreensão do nível de maturidade da organização e com base na revisão da literatura, definiu-se as características do EGP de desenvolvimento de competências em gerenciamento de projetos;
- Divulgação do EGP: após estabelecidas as necessidades organizacionais quanto ao EGP proposto, esta etapa consiste na promoção do EGP, demonstrando os benefícios e as mudanças que sua implantação poderá agregar à empresa. Nesta etapa, as partes envolvidas devem estar conscientes do que representará a criação de um EGP na empresa e o que este vai agregar de valor na cultura organizacional;

- Implantação do escritório: tem objetivo de entregar a estruturação física do EGP em relação ao seu local físico de instalação, toda infraestrutura necessária para seu funcionamento e a definição dos recursos que serão de responsabilidade do EGP;

- Estruturação do EGP: este grupo de entregáveis consiste na montagem da equipe que atuará no EGP. Aqui pretende-se criar a metodologia a ser adotada para o gerenciamento dos projetos, a definição das 
ferramentas que serão utilizadas pela organização, elaboração de processos e manuais para promover a capacitação;

- Implantação: é nesse grupo de entregáveis que o EGP será implantado, através de um projeto piloto, já com uso das metodologias e ferramentas definidas. Aqui será definido o programa de projetos que ficará sob a responsabilidade do EGP para a implementação da metodologia desenvolvida;

- Capacitação: consiste na capacitação dos recursos da organização que atuarão diretamente no EGP ou que serão atingidos por sua atuação (gerentes e equipe de projetos). A capacitação consiste no desenvolvimento de treinamentos internos, workshops, brainstorming e demais atividades relacionadas à gestão do conhecimento. Dentro do grupo de entrega estarão inseridos além da capacitação, a definição de avalições periódicas e implantação de feedbacks para os recursos humanos dos projetos, com a finalidade de desenvolvimento do quadro técnico da organização.

Aubry (2015) menciona que a mudança organizacional é um processo evolutivo capaz de melhorar não apenas o desempenho e a maturidade do gerenciamento de projetos, mas também o desempenho dos negócios. Para promover mudanças organizacionais na empresa em estudo, alguns fatores possuem influência direta na proposta de implantação do EGP e deverão ser observados durante o seu processo.

Será imprescindível o apoio da diretoria da empresa para dar legitimidade e delegar aos responsáveis pela implantação, a autoridade necessária para o sucesso deste projeto organizacional. Este apoio tem impacto direto no engajamento dos colaboradores durante o desenvolvimento da nova cultura organizacional proposta.

O conhecimento do perfil de maturidade em gerenciamento de projetos da empresa permitiu definir qual a forma mais adequada de atuação do EGP na organização. A definição das metodologias deverá ser simples, pragmática e aderente aos objetivos estratégicos da empresa observando o seu porte e o seu segmento de atuação. Esses aspectos são relevantes para garantir a boa recepção pelos praticantes.

A definição dos papéis e responsabilidades deverão ser compatíveis com os recursos e as habilidades das equipes, considerando a lacuna de conhecimento identificada na análise de resultados. Em ambientes com muitos projetos sendo executados paralelamente, como a empresa a que se propõe este estudo, será comum pouca dedicação ao EGP, portanto é importante que haja exclusividade dos envolvidos com o EGP de forma que possam atender as demandas dos gerentes de projetos, manter a padronização e as métricas definidas.

Visto o exposto, de acordo com Sergeeva e Ali (2020), a aprendizagem em 
organizações baseadas em projetos representa um sistema de mecanismos e atores que trabalham juntos e se influenciam, onde o EGP desempenha um papel central na formação de uma estrutura que suporta os fluxos de aprendizado entre os níveis organizacionais. Segundo os autores, três grupos de atores: gerentes de projetos, líderes seniores e EGP se envolvem cada um à sua maneira no processo de aprendizagem, dependendo do seu grau de engajamento e poder na organização, enquanto o EGP oferece a mais poderosa capacidade de intermediação de conhecimento para permitir o fluxo do aprendizado.

\section{Conclusões e sugestões de estudos futuros}

$\mathrm{O}$ assunto gerenciamento de projetos como um processo baseado em boas práticas, envolvendo o uso de metodologias e ferramentas consistentes, ganha cada vez mais espaço nas organizações. No entanto, a implantação, o aumento do nível de maturidade e o desenvolvimento de um processo de melhoria contínua ligado à essa área, ainda são temas de debate constante visto a evolução e os desafios apresentados pelo ambiente de negócios.

$\mathrm{O}$ presente estudo evidenciou que a empresa analisada apesar do longo tempo no desenvolvimento de projetos, ainda possui uma cultura organizacional inexpressiva quanto ao uso de boas práticas em gerenciamento de projetos visto o nível de maturidade identificado como Inicial. Apesar de possuir bom relacionamento com seus clientes nos pilares de custo e tempo de entrega dos projetos (atendimento aos prazos estreitos dos clientes), acredita-se que a melhora no planejamento dos projetos agregará na qualidade das entregas de forma significativa, redução do tempo no desenvolvimento das atividades e atendimento integral ao escopo, permitindo um gerenciamento da carteira de projetos mais consistente e por consequência capaz de aumentar a competitividade no mercado para captação de novos clientes.

Com base na revisão da literatura, pôde-se inferir que a implantação de um EGP orientado ao desenvolvimento de competências em gerenciamentos de projetos pode trazer benefícios para a organização e também contribuir com a melhoria da maturidade em gerenciamento de projetos, trazendo à cultura organizacional as ferramentas necessárias para gerir seu portfólio, programas, projetos e recursos.

O estudo apresenta oportunidades para demais organizações do mesmo segmento e que possuem problemas similares aos aqui descritos no gerenciamento de seus projetos. Sugere-se que a investigação do nível de maturidade em gerenciamento de projetos através do MMGP e da percepção das equipes envolvidas nos projetos são instrumentos capazes de diagnosticar as mudanças organizacionais necessárias para cumprir com os objetivos dos projetos. Neste trabalho, o modelo proposto para a implantação do EGP foi a solução encontrada na literatura para a empresa em epígrafe, podendo ser utilizado 
como referência para as demais organizações do setor.

\section{Referências}

Almeida, N. de O., \& Neto, R. O. (2015). Gestão Profissional do Portfólio de Projetos: Maturidade e indicadores. Brasport.

Anantatmula, V. S. (2010). Project manager leadership role in improving project performance. Engineering Management Journal, 22(1), 13-22.

Anantatmula, V. S., \& Rad, P. F. (2018). Role of organizational project management maturity factors on project success. Engineering Management Journal, 30(3), 165-178.

Andersen, B., Henriksen, B., \& Aarseth, W. (2006). Project Management Office Establishment Best Practices. Project Perspectives, 30 .

Aubry, M., \& Hobbs, B. (2011). A fresh look at the contribution of project management to organizational performance. Project Management Journal, 42(1), 3-16.

Aubry, M. (2015). Project management office transformations: Direct and moderating effects that enhance performance and maturity. Project Management Journal, 46(5), 19-45.

Backlund, F., Chronéer, D., \& Sundqvist, E. (2014). Project management maturity models - A critical review: A case study within Swedish engineering and construction organizations. Procedia-Social and Behavioral Sciences, 119(0), 837-846.

Bredillet, C., Tywoniak, S., \& Tootoonchy, M. (2018). Exploring the dynamics of project management office and portfolio management co-evolution: A routine lens. International journal of project management, 36(1), 27-42. de Souza, T. F., \& Gomes, C. F. S. (2015).

Assessment of maturity in project

management: a bibliometric study of main models. Procedia Computer Science, 55, $92-$ 101.

Desouza, K. C., \& Evaristo, J. R. (2006). Project management offices: A case of knowledge-based archetypes. International Journal of Information Management, 26(5), 414-423.

Fernandes, G. F. P., \& Garcez, M. P. (2019). Contribuição da maturidade da gestão de projetos para a geração de vantagem competitiva em empresas de telecomunicações. Revista de Gestão e Projetos-GeP, 10(2), 25-39.

Görög, M. (2016). A broader approach to organisational project management maturity assessment. International Journal of Project Management, 34(8), 1658-1669.

Hobbs, B., \& Aubry, M. (2007). A multi-phase research program investigating project management offices (PMOs): the results of phase 1. Project Management Journal, 38(1), 74-86.

Irfan, M., Hassan, M., Hassan, N., Habib, M., Khan, S., \& Nasruddin, A. M. (2020). Project Management Maturity and Organizational Reputation: A Case Study of Public Sector Organizations. IEEE Access, 8, 73828-73842.

Jalal, M. P., \& Koosha, S. M. (2015). Identifying organizational variables affecting project management office characteristics and analyzing their correlations in the Iranian project-oriented organizations of the construction industry. International Journal of Project Management, 33(2), 458-466.

Jerbrant, A. (2014). A maturation model for project-based organisations-with uncertainty management as an ever-present multiproject management focus. South African Journal of Economic and Management Sciences, 17(1), 33-51. 
Khalema, L. S., Van Waveren, C. C., \& Chan, K. Y. (2015). The relationship between project management office maturity and organisational project management maturity: An empirical study of the South African government infrastructure departments. South African Journal of Industrial Engineering, 26(3), 12-26.

Ko, J. H., \& Kim, D. (2019). The Effects of Maturity of Project Portfolio Management and Business Alignment on PMO Efficiency. Sustainability, 11(1), 238.

Kwak, Y. H., Sadatsafavi, H., Walewski, J., \& Williams, N. L. (2015). Evolution of project-based organization: A case study. International Journal of Project Management, 33(8), 1652-1664.

Martins, H. C., Moura, M. T., \& de Mesquita, J. M. C. (2011). Escritórios de projetos como resposta estratégica da organização: um estudo de caso na Vale. Revista de Gestão e Projetos - GeP, 2(2), 26-52.

Maturity Research (2020). Fundamentos do Modelo de Maturidade Prado-MMG. Recuperado em 05/08/2020 de: https://www.maturityresearch.com/novosite/

Monteiro, A., Santos, V., \& Varajão, J. (2016). Project management office models-a review. Procedía computer science, 100, 1085-1094.

Müller, R., Drouin, N., \& Sankaran, S. (2019). Modeling organizational project management. Project Management Journal, 50(4), 499-513.

Oliveira, C., Tereso, A., \& Fernandes, G. (2017). PMO Conceptualization for Engineering and Construction Businesses. Procedia computer science, 121, 592-599.

Oliveira, R. R., \& Martins, H. C. (2018). Estratégia, Pessoas e Operações como agentes influenciadores do desempenho do Escritório de Gerenciamento de Projetos: uma análise por meio da Modelagem de
Equações Estruturais. Gestão \& Produção, 25(2), 410-429.

Otra-Aho, V. J., Iden, J., \& Hallikas, J. (2019). The Impact of the Project Management Office Roles to Organizational Value Contribution. International Journal of Information Technology Project Management (IJITPM), 10(4), 79-99.

Prado, D. (2015). Maturidade em gerenciamento de projetos. Nova Lima: INDG Tecnologia e Serviços Ltda, 7.

Project Management Institute (PMI), (2017). A guide to the project management body of knowledge (PMBOK guide) (Vol. 6). Project Management Inst.

Rodrigues, I., Júnior, R. R., \& Csillag, J. M. (2006). Os escritórios de projetos como indutores de maturidade em gestão de projetos. Revista de AdministraçãoRAUSP, 41(3), 273-287.

Sergeeva, N., \& Ali, S. (2020). The role of the Project Management Office (PMO) in stimulating innovation in Projects initiated by Owner and Operator Organizations.

Project Management Journal, 8756972820919215.

Szalay I., Kovacsb A., \& Sebestyenc Z. (2017). Integrated Framework for Project Management Office Evaluation. Procedia Engineering, 196, 578-584.

Too, E. G., \& Weaver, P. (2014). The management of project management: A conceptual framework for project governance. International Journal of Project Management, 32(8), 1382-1394.

Winter, M., \& Szczepanek, T. (2008). Projects and programmes as value creation processes: A new perspective and some practical implications. International Journal of Project Management, 26(1), 95-103. 